\title{
E-BUSINESS: TEKNOLOGI DAN PELUANG BISNIS DI INDONESIA
}

\author{
Chandra Wibowo Widhianto ${ }^{1}$
}

\begin{abstract}
Information technology offers creativity and business inovation rapidly and easily. A business must see the new opportunity. Microsoft give solution that will "spoil" business man in implementation, management, and the exploitation of the information technology maximally. The information technology is cheap and easy to applied now.
\end{abstract}

Keywords: e-Business, technology, opportunity, business

ABSTRAK
Teknologi Informasi menawarkan kreativitas dan inovasi bisnis secara cepat dan mudah.
Bisnis harus melihat peluang baru perkembangan itu. Solusi yang ditawarkan oleh microsoft
akan "memanjakan" pebisnis dalam implementasi, mengelola, serta mengeksploitasi teknologi
informasi secara lebih maksimal. Teknologi informasi yang dahulu terkesan mahal (cost-center)
dan sulit diterapkan menjadi makin murah dan gampang.
Kata kunci: e-business, teknologi, peluang, bisnis

${ }^{1}$ Staf Pengajar Fakultas Ekonomi, UBiNus, Jakarta 


\section{PENDAHULUAN}

\section{Latar Belakang dan Tujuan}

Di pasar global 2002 sekarang ini, banyak perubahan yang telah tejadi dan perubahan tersebut berdampak multidimensional. Perubahan yang paling mendasar adalah dalam bidang bisnis seiring dengan perkembangan internet yang malah semakin pesat, jauh melampaui apa yang dipikirkan satu tahun kemarin sehingga dirasakan internet akan (mulai) menjadi "backbone” dalam "harnpir" semua bidang bisnis. Jadi, dapat secara cepat disimpulkan bahwa perkembangan ekonomi (bisnis) sedang menurun dengan banyak terjadinya krisis ekonomi tetapi internet justru berkembang naik dengan cepat. Berpijak dari sinilah maka ada celah peluang yang justru dapat diambil di dalam berbisnis, yaitu dengan seni bisnis, konsep, dan metode, serta pola pikir dilandasi dengan penguasaan dan mengeksploitasi teknologi informasi atau yang lebih dikenal dengan e-Commerce dan $e$-Business.

Gelombang bisnis digital atau berbasis teknologi informasi telah melahirkan fenomena paradigma bisnis baru dengan modal intelektualitas cerdas dan kreatif. Era internet telah membuat banyak kegiatan/bisnis yang berhubungan dengan internet berkembang. Saat ini, banyak calon wirausahawan, pengusahan profesional, akademisi lembaga nonprofit, dan investor yang sudah dan akan masuk ke berbagai kegiatan/usaha yang berkaitan dengan internet. Narnun, disisi lain, dukungan dari pemerintah di bidang Teknologi Informasi juga relatif masih lemah. Infrastruktur elektronik dan komunikasi rnasih sangat minimal dan kalaupun ada, nilai jual layanan tersebut masih sangat mahal sehingga terkadang berkesan eksklusif.

Disisi lain, semangat para wirausahawan untuk lebih meningkatkan skala bisnisnya serta ekspansi secara globalisasi, dan perkembangan teknologi informasi yang juga tidak dapat dibendung lagi, menyebabkan lambatnya kemajuan infrastruktur di Indonesia "mungkin" tidak begitu berpengaruh. Justru dengan kesulitan yang ada, para pebisnis justru ditantang untuk lebih kreatif mencari solusi alternatif dalam menyeimbangkan perkembangan teknologi informasi. Artikel ini dibuat untuk melihat perkembangan teknologi yang dimulai dari evolusi komputer (PC) masa lalu, sekarang, dan akan datang. Karena dengan melihat evolusi teknologi informasi itulah dan dipadukan dengan kebutuhan para pebisnis terhadap teknologi informasi, dapat terlihat pola bisnis dan cara mengantisipasinya secara cepat dan bijaksana.

\section{Pokok Permasalahan}

Tren bekomputer dimulai sekitar sepuluh tahun yang lalu. Sekarang, komputer digunakan untuk mendukung proses bisnis. Namun, terdapat perubahan fenomena baru, yaitu bisnis tidak dapat berjalan tanpa komputer (teknologi informasi). Bahkan, teknologi informasi diperkirakan akan mengendalikan semua arah dari pola bisnis.

\section{Tujuan}

Tujuan artikel ini menjelaskan awal mula komputer (khususnya Indonesia) hingga prediksi di masa depan. Sekarang pebisnis harus cepat tanggap dan beradaptasi secara cepat. Dengan mengetahui pola perkembangan bisnis, para eksekutif diharapkan dapat mengambil keputusan strategis pada area bisnisnya masing-masing. 


\section{Ruang Lingkup}

Dengan asumsi para pembaca sudah mengetahui e-Business, e-Commerce, dan internet, hanya dilaskan ketiga hal itu sekilas saja. Diulas tentang pula tentang tools yang dapat digunakan untuk implementasi bisnis ke internet secara cepat dan murah tetapi sangat powerful, yaitu Microsoft Visual Studio.NET. ulisan ini ditujukan untuk para manajer/eksekutif yang biasa mengambil keputusan manajerial secara strategis. Untuk keterangan lebih lanjut tentang Microsoft Visual Studio .NET. dapat dilihat di situs http://www.microsoft.com/ .

\section{PEMBAHASAN}

\section{Evolusi Teknologi}

\section{Kekuatan Berkomputer (Kondisi dan Perkiraan PC)}

Perkembangan personal komputer (PC) di Indonesia diawali pada sekitar tahun 1980-an dengan prosesor 8088 (XT) memori $640 \mathrm{~Kb}$, perangkat lunak Microsoft Wordstar, Lotus 1-2-3, dan dBase III+. Komputer itu langsung menggebrak dunia bisnis dan bertahan dengan tenggang waktu yang cukup lama (sekitar tahun 1990-an) walaupun sekitar tahun 1988-an mulai muncul PC AT (prosesor 286, 386sx, 386dx, 486sx, 486dx dengan kapasitas memori antara 1 hingga $8 \mathrm{Mb}$ ). Harga itu PC AT itu sangat mahal. Kemahalan harga itu dapat digantikan fungsinya oleh PC XT sehingga masih terkesan eksklusif untuk bisnis.

Program yang ada mulanya menggunakan PC-DOS atau MS-DOS, mulai berubah ke Microsoft Windows meskipun pada awal peluncuran perdananya perusahaan dan organisasi mulai melirik Windows di atas 1990-an karena kebutuhan bisnis yang semakin besar, program Wordstar, Lotus, dan dBase III+ mulai digantikan oleh kecanggihan Microsoft Office dan Lotus Smart Suite kala itu dengan operating system MS Windows. Namun harus diakui, investasi yang harus dikeluarkan untuk migrasi dari DOS ke Windows cukup besar terutama untuk pembelian perangkat komputer (hardware). Perangkat komunikasi untuk menunjang "kepiawaian” yang ditawarkan oleh Windows pun masih sangat mahal. Jadi, tahap ini kemajuan dan pemakaian teknologi informasi untuk berbisnis masih dirasakan sangat mahal dan terkesan sebagai pemborosan saja sehingga TI dianggap sebagai cost center.

Sekitar tahun 1994-an, harga PC mulai menurun karena banyak produsen komputer mulai ikut dalam kancah persaingan perakitan industri komputer. Negara Taiwan, Singapura, bahkan Malaysia mulai berlomba merakit komputer yang dikenal dengan istilah PC Jangkrik. Walaupun harga $P C$ di Indonesia semakin murah, perangkat komunikasi dan biaya untuk berkomunikasi masih tetap mahal. Jadi, banyak komputer yang beroperasi sebagai single user PC saja.

Dengan kata lain, integrasi diantara sistem komputer masih sangat jarang. Komputer hanya sebagai dukungan operasi sebuah organisasi/perusahaan saja. Perubahan besar-besaran mulai dirasakan sejak dikeluarkanya Microsoft Windows 95 dengan dukungan fasilitas internet explorer secara pengaturan jaringan network yang semakin mudah. Para penguna komputer mulai merasakan suatu sensasi yang berbeda. Dari situlah, mulai terasa bahwa komputer tidak hanya mendukung operasi tetapi dapat menjadi suatu keunggulan bersaing dalam bisnis. Kemudahan dan 
fasilitas yang ditawarkan makin "memanjakan" para penggunanya. Suatu gebrakan besar saat dunia dapat saling terhubung melalui jaringan internet.

Namun, biaya komunikasi yang harus dikeluarkan untuk akses internet masih cukup mahal kala itu. Kecepatan bandwidth pun masih sangat minimal (dimulai dari 9 hingga 11 Kbps). Service yang terdapat di internet pun masih sebatas text dan sedikit gambar diam saja. Lonjakan yang sangat besar dan cepat terjadi pada kecepatan internet langsung melejit sampai 33,6 Kbps dan sekarang 56,6 Kbps. Tolok ukurnya adalah kecepatan yang dapat dicapai sebuah modern.

Dengan demikian, fenomena berkomputer sudah mulai berubah seperti berikut.

1. Akses internet cepat aksesnya dan biayanya semakin murah.

2. Single user PC berubah ke multi user PC.

3. Kecepatan PC Pentium bergerak naik hanya dalam hitungan bulan.

4. Produksi PC per tahun naik secara ganda (double).

Namun mulai tahun 2002, arah perkembangan komputer (teknologi informasi) akan berubah seperti berikut ini.

1. Pengguna home $P C$ akan berubah ke mobile $P C$ dan hal itu sudah terjadi.

2. Perangkat komunikasi akan berubah dari wire ke wireless sedang dirintis.

3. Munculnya cara baru berbisnis seperti elektronik bisnis atau elektronik commerce dengan dukungan internet.

4. Dari mobile PC ke PDA, handphone, mobilephone, dan lain - lain yang saat ini sedang dirintis.

5. Dari $e$-Business dan $e$-Commerce ke $m$-Business atau $m$-Commerce yang akan menjadi trendi masa yang akan datang.

\section{Konektivitas dan Integrasi Bisnis Global Secara Online}

Pasar bisnis mulai dapat menangkap menangkap peluang yang ditawarkan oleh teknologi ini tidak dapat ditembus oleh para pebisnis seperti waktu, jarak, dan ruang. Sekarang, bisnis dapat dilakukan selama 24 jam sehari, 7 hari seminggu, 365 setahun penuh tanpa istirahat sedikit pun. Telah ada pasar bisnis baru, yaitu pasar di internet (I-Market). Terdapat dua jenis I-Market, yaitu B2B dan B2C. Perkembangan elektronik bisnis itu mendorong munculnya perantara elektronik (cyber broker atau cyber intermediaries). Perantara elektronik itu kian menyemarakan dan mendukung perkembangan bisnis secara elektronik. Para pemain bisnis seperti B2B dan B2C tidak kesulitan mencari konsumen baru.

Dengan menghubungkan jaringan intranet dan ekstranet ke internet, suatu perusahaan/organisasi dapat melakukan bisnis secara online. Tanpa harus menambahkan perangkat keras maupun lunak, dapat berhubungan langsung ke internet dengan mudah. Melalui media internet, bisnis akan berubah menjadi bisnis global. Selain jarak, waktu, dan ruang, media internet secara otomatis dapat mengurangi biaya transaksi (hingga 99\%). Konsumen pun lebih merasa dimanjakan karena salah satu fokus utama dalam berbisnis di internet adalah kebutuhan dan kemauan pelanggan. 


\section{Organisasi Maya (The Virtual Company)}

\section{Enterprise Teknologi Informasi}

Teknologi informasi dibutuhkan informasi untuk memusatkan suatu kegiatan bisnis, melakukan bisnis dengan baik dan benar, serta menciptakan kreativitas (inovasi) baru atau nilai baru. Teknologi informasi menjadi keunggulan bersaing bagi perusahaan dalam dunia persaingan bisnis yang semakin ketat. Penggunaan teknologi informasi tidak hanya dimonopoli perusahaan besar saja karena banyak perusahaan skala kecil menengah yang menggunakan teknologi informasi terutama untuk efisiensi. Berikut ini tantangan baru teknologi informasi sebagai pusat bisnis.

1. Menghubungkan organisasi maya (The Virtual Company).

2. Adaptasi terhadap perubahan bisnis secara cepat.

3. Menghantarkan nilai baru dari lini atas lini bawah dalam suatu organisasi.

Hal penting yang harus selalu diperhatikan dalam mengeksploitasi teknologi informasi di organisasi adalah berusaha lebih efisien daripada para pesaing.

\section{Perkembangan Organisasi Maya}

Organisasi maya adalah suatu perusahaan yang menggunakan teknologi informasi untuk menghubungkan (link) orang, aset, dan pemikiran (knowledge) dari berbagai rekan bisnis, sumber daya manusia tanpa batas ruang, jarak, dan waktu dalam mengeksploitasi kesempatan bisnis. Di organisasi maya, setiap departemen dan aspek ditransformasikan dari proses yang terpisah (pada mulanya) ke penyatuan proses (integrasi). Pada awalnya, departemen personalia, keuangan, pemasaran dan lain-lain.

Bekerja secara sendiri-sendiri (mempunyai target tersendiri) serta lokasi khazanah data (database) yang tersebar pada masing-masing departemen dan lokasi. Dengan adanya integrasi, target masing- masing departemen tersebut berubah menjadi satu visi dan misi perusahaan/organisasi secara utuh dan khazanah data pun menjadi terpusat. Hal itu disebut dengan membangun manajemen knowledge. Karakteristik organisasi maya yang sukses meliputi adaptability, opportunism, excellence, teknologi, borderless, dan trust-based. Secara teknis, proses pemeliharaan data pun akan menjadi lebih mudah, murah, dan cepat. Salah satu biaya terbesar dalam pemakaian teknologi informasi adalah biaya pemeliharaan.

Biasanya, proses integrasi dilakukan dengan proses rekayasa ulang bisnis (Business Process Reengineering/BPR). Semua unit proses bisnis dievaluasi kembali dan ditinjau ulang. Suatu unit harus dihapuskan bila tidak efektif. Jika ada unit yang efektif tapi tidak efisien, harus dilakukan perubahan pola kerja agar menjadi lebih efisien, harus dilakukan perubahan pola kerja agar menjadi lebih efisien. Tujuan utama BPR adalah perubahan secara radikal dengan tingkat kenaikan keuntungan secara ganda. Tidak hanya 10\%, 30\%, atau 70\%, tetapi harus secara $100 \%$ atau 200\%. Suatu penentuan ukuran standar harus dibuat untuk melihat perubahan yang dihasilkan oleh BPR. Fokus BPR untuk mereorganisasi agar siap melakukan proses bisnis yang baru.

Di dalam e-Business, integrasi dilakukan diarea departemen produksi dan proses penyediaan/order bahan baku. Selanjutnya, di area sales, employee self-service (dengan implementasi Human Resource Information System), dan area layanan pelanggan (Customer 
Relationship Management/CRM). Proses terkahir adalah area dukungan operasi seperti keuangan dan personalia tetapi dengan orientasi ke pelanggan.

\section{Implikasi, Tantangan, dan Perubahan}

Digitalisasi arus informasi adalah tujuan utama integrasi dan organisasi maya. Jika dahulu data atau informasi tersebar menjadi "pulau informasi", tugas integrasi adalah menyatukan dan menghubungkan "pulau informasi" tersebut. Aplikasi (software) yang digunakan pun berubah dari single-application menjadi multi application, multi company, dan multi audience. Dengan adanya gabungan serta keanekaragaman aplikasi itu, dituntut pula suatu media untuk standarisasi, yaitu internet. Protokol internet dapat digunakan secara global. Akan tetapi, timbul masalah dan konflik untuk penyatuan itu sebagai berikut.

1. Sistem yang ada tidak di desain untuk bekerja secara bersama - sama.

2. Proses kerja antar aplikasi yang tidak berkesinambungan.

3. Biaya integrasi mahal dan memerlukan waktu yang lama sangat berisiko untuk gagal.

4. Hanya terfokus pada efisiensi dan terlalu banyak cost cutting.

5. Tidak terlalu memperhatikan sudut pandang konsumen (pelanggan).

6. Suka meniru ide pesaing (bisnis membutuhkan ide yang selalu baru).

7. Gambaran proyek organisasi yang terlalu lebar (respon untuk tindakan menjadi lambat).

8. Frequently untuk reorganisasi (agar para manajer lebih konsisten).

9. Terlalu banyak konsultan luar yang terlibat (konsultan TI biasanya lebih fokus ke benefit dan perubahan teknologi informasi).

\section{Virtual Private Networking}

Dengan menghubungkan jaringan lokl (intranet dan ekstranet) ke jaringan publik (internet), memiliki risiko seperti penyadapan (sniffed) oleh orang yang tidak bertanggung jawab. Oleh karena itu, diterapkan teknologi yang dapat menghubungkan antara dua buah komputer (jaringan) secara aman melalui jaringan internet, yaitu denga VPN.

VPN adalah sebuah teknologi untuk menciptakan koneksi aman antara dua buah bagian pada jaringan privat yang menggunakan sarana jaringan internet sebagai sarana komunikasinya sehingga biaya koneksi dapat ditekan seminimal mungkin. VPN ditempatkan pada kedua ujung segmen dari jaringan privat yang saling terhubungi.

Digunakan dua teknologi utama, yaitu tunneling dan enkripsi. Tunneling adalah teknologi yang membuat semacam jalur khusus bagi dua buah segmen jaringan (lorong) untuk melewatkan paket data. Sistem itu akan memperkecil terjadinya penyadapan. Enksripsi adalah teknologi untuk mencapai mengacak paket data. Apabila paket data itu tertangkap oleh pihak lain, tidak akan dapat mengakses data tersebut secara utuh dan sempurna.

VPN dapat berupa software (router atau firewall misalnya www.zonelabs.com) atau hardware (mesin/perangkat keras). Masa depan penggunaan VPN akan semakin banyak karena menggunakan koneksi internet yang murah dan cepat. Untuk informasi lebih lanjut mengenai VPN, dapat dilihat pada situs www.vpnlabs.com atau situs vendor, hardware, dan software VPN terkemuka. 


\section{Strategi Untuk Organisasi Maya}

1. Sharing infrastruktur dan risiko.

2. Adanya link antarberbagai kompetensi utama.

3. Mengurangi "concept-to-cash time" melalui sharing.

4. Meningkatkan fasilitan dan cakupan pasar.

5. Adanya akses ke pasar baru atau memperoleh loyalitas pelanggan.

6. Beralih dari menjual produk ke menjual solusi.

\section{Kunci Untuk Persaingan Bisnis yang Tepat}

Agile competition adalah kemampuan perusahaan untuk beroperasi untung dalam lingkungan kompetitif yang mencakup perubahan preferensi pelanggan, kondisi pasar, dan kesempatan bisnis yang berlangsung secara terus menerus dan untuk predictable. Hambatan utama performansi agile competition adalah arus informasi internal maupun antar perusahaan. Kemasan informasi, penyediaan akses ke informasi, dan penyediaan tools menjadi produk yang sangat berharga.

\section{Pelanggan}

Fokus ke pelanggan adalah kunci utama untuk sukses dalam persaingan bisnis yang semakin ketat terutama di dalam e-Bisnis. Pelanggan biasanya ingin berbisnis secara kontinu berdasarkan aspek kecepatan, kemudahan, personalisasi/individu, dan harga. Produsen harus memperhatikan apabila produk/jasa yang ditawarkan sudah memenuhi kebutuhan dan prioritas pelanggan. Faktor lain yang harus diperhatikan yakni berbisnis di internet mempunyai entri barrier yang sangat rendah sekali. Artinya, setiap saat akan muncul pesaing bisnis baru. Pelanggan dapat mengunjungi took online secara cepat. Secara otomatis, produsen mendapatkan pelanggan baru secara cepat juga.

Pasar internet berarti pasar global (international). Target pangsa pasar sangat besar serta dituntut untuk selalu berinovasi, berkreasi, membuat produk/jasa yang fleksibel, dan customization. Produk massal mungkin tidak cocok untuk di jual di pasar itu. Kebutuhan pelanggan di Indonesia berbeda dengan kebutuhan pelanggan di Amerika Serikat.

Melalui pelanggan, dapat diprediksi pola penjualan dan produksi di masa yang akan datang. Produk/jasa apa yang kira-kira akan dibeli oleh pelanggan dan berapa unit jumlah pembeliannya. Penggunaan teknologi informasi yang menyimpan dan mengolah khazanah data pelanggan dengan sistem penunjang keputusan (decision support), akan mengerjakan hal itu secara otomatis.

\section{Sumber Daya Manusia dan Masa Kini}

Kunci utama selanjutnya adalah karyawan. Karyawan merupakan aset berharga bagi setiap perusahaan. Kunci keberhasilan kerja perusahaan tergantung pada karyawan itu sendiri. Dengan merekrut karyawan smart dan mempunyai knowledge akan menghasilkan keputusan bisnis strategis yang smart pula. Itu semua membuat proses kerja (rantai nilai) yang semakin efisien. 


\section{Teknologi Informasi}

Technology should be an enable. Untuk dapat mengikuti persaingan bisnis yang semakin ketat, teknologi informasi merupakan keharusan yang tidak dapat ditawar- tawar lagi. Perusahaan tanpa teknologi informasi dapat dipastikan lambat laun akan ketinggalan. Teknologi informasi akan "membuka" kreativitas dan fleksibilitas untuk inovasi produk/jasa di masa depan.

Teknologi informasi dapat menghubungkan perusahaan dengan pelanggan (melalui internet, mobilephone, PDA, dan lain - lain), partner kerja (melalui jaringan EDI, internet, dan lain - lain), bahkan menghubungkan dan memperkuat para karyawan itu sendiri. Akhirnya, teknologi informasi akan menangkap dan menciptakan nilai bisnis yang lebih pada setiap tingkatan di suatu organisasi sebagai berikut.

1. Pada lini bawah: menyelesaikan banyak pekerjaan dengan lebih cepat.

2. Pada lini atas: menciptakan new values dari aset organisasi yang sudah ada maupun yang baru ada (knowledge management).

\section{Realita Perubahan}

\section{Bisnis Hari ini adalah e-Business}

Rumus dasar e-Business/e-Commerce adalah teknologi informasi + bisnis. Definisi eBusiness/e-Commerce sangat beragam dan sudah banyak diketahui orang. Terdapat dua macam interaksi utama dalam e-Business, yaitu B2C dan B2B. Secara prinsip, cara kerjanya tidak jauh berbeda sehingga sulit dibedakan. Berikut ini cara mudah membedakan B2C dan B2B.

1. B2C adalah interaksi antara orang (customer/pelanggan) dengan program (situs web, ATM, dan lain-lain). Dengan kata lain, data berasal dari orang lain.

2. B2B adalah interaksi antara program dengan program. Terdapat keterkaitan dan ketergantungan yang sangat erat antara aplikasi, sistem, dan subsistem. Integrasi (lihat virtual company) adalah model bisnis B2B.

Untuk membangun dan merawat (maintenance) interkasi diantara program dengan program, memerlukan biaya mahal, waktu dan proses yang lama, serta konsumsi sumber daya yang banyak. Organisasi sering mengalami "sakit kepala" membangun atau merawat interaksi dan integrasi itu. Dahulu, pebisnis (organisasi) mempunyai sistem kerja (TI) yang tertutup (sistem yang khusus/spesial), begitu juga dengan partner bisnis yang lain. Jika berusaha menyatukan (integrasi) semua sistem dan subsistem itu, akan menyebabkan timbulnya konflik (kerusakan) karena aplikasi itu didesain untuk berdiri sendiri.

\section{Harapan Konsumen}

Biasanya nilai harapan seorang konsumen pasti akan selalu berada di atas realita yang ada. Dengan kata lain, sebagus dan sesempurna apapun produk/jasa yang dapat diberikan konsumen, belum 100\% memuaskan konsumen. Integrasi proses sebuah organisasi bisnis akan menghasilkan produk/jasa yang berkualitas baik, singkat, serta harga yang bersaing. Jadi, penggunaan teknologi melalui solusi terpadu dan terintegrasi dapat menawarkan yang superior. 


\section{Apa yang Dibutuhkan}

Suatu bisnis harus mempunyai kemampuan secara cepat dan fleksibel untuk memilih partner kerja, sistem, dan aplikasi yang terbaik. Oleh karena itu, dibutuhkan sumber daya manusia yang andal khususnya dalam bidang teknologi. Berikut ini tantangan yang harus dihadapi para pebisnis.

1. Pelanggan/konsumen yang mobile.

2. Hubungan dengan partner kerja dan vendor dagang yang harus baik.

3. Sumber daya manusia (karyawan) yang smart dan mobile.

4. Isu penting lainnya adalah regulasi, marketplace, kompetisi, dan ekonomi makro.

\section{Solusi dan Microsoft}

\section{Infrastruktur E-Bisnis}

E-Businss adalah dasar (pondasi) untuk sebuah kesuksesan suatu infrastruktur bisnis organisasi pada masa sekarang dan akan datang. Terdapat beberapa kriteria yang digunakan, yaitu reliable, scrable, dan manageable. Membuat business-value yang berguna dalam memperkuat posisi bisnis organisasi seperti berikut.

1. Semua lingkungan kerja yang dapat mengakses data - data misi organisasi yang kritikal.

2. Menjadi pondasi untuk kolaborasi di antara para karyawan.

3. Menjadi pondasi untuk layanan dan kerja sama yang erat antara pelanggan dan partner kerja.

\section{Microsoft Enterprise Software}

Microsoft Enterprise Software adalah sekumpulan paket perangkat lunak dari Microsoft agar terhubung dengan dunia informasi (people, sistem, dan peralatan), yaitu Microsoft Visual Studio, Microsoft Enterprise Servers, dan Microsoft Windows XP. Solusi utama yang ditawarkan dari pihak Microsoft sebagai berikut.

1. Integrasi partner bisnis untuk supplier dan manajemen pengadaan.

2. Empowering, employees terdiri dari corporate intranets, mobile communications, project collaboration and analysis, retail analytics, sales and marketing analytics.

3. Hubungan dengan pelanggan seperti bisnis di internet dan internet bisnis retail extension.

4. Infrastruktur e-business terdiri dari pengembangan, manajemen, dan arsitektur sistem.

\section{Microsoft. Net}

Terdapat tiga pilar dasar Microsoft. NET seperti berikut.

\section{XML Web Services}

Merupakan suatu perubahan besar (evolusi) situs web karena dapat digunakan untuk pemrograman (service) sekaligus teks, display, dan gambar. Selain itu, program/aplikasi yang biasanya hanya ada di server saja, saat ini telah berdasarkan dapat didistribusikan ke pengguna (users). Dengan begitu, "kerja” server dapat dikurangi dan proses output lebih cepat. 
Kemampuan yang hebat adalah protokol open semua di layer seperti http://atau XML Web Service sebagai lingua-franca untuk integrasi. Mempunyai data format yang universal (sistem dapat saling "berbicara" satu sama lain) dan merupakan dasar untuk standar interaksi sistek (SOAP=interskasi, WSDL=description, UDDI=directory).

2. New applications $=$ Clients + Servers + Services

Dahulu, aplikasi adalah clients + servers. Namun, aplikasi saat ini adalah clients + servers + services. Artinya, tidak perlu membuat suatu program aplikasi secara berulang-ulang tetapi dapat memakai suatu aplikasi untuk proses yang lain sekaligus di outsource. Dengan paradigma baru itu, pengambilan keputusan teknis yang biasanya dilakukan orang TI dapat dilakukan pula oleh manajerial (eksekutif).

\section{Great User Experience}

Suatu contoh kasus yang cukup sukses dan terkenal adalah yahoo. Yahoo.com tidak membuat aplikasi sendiri tetapi menggunakan banyak outsource. Yahoo adalah Web Service Consumer yang berfokus pada content aggregator dan service aggregator.

\section{Tanggapan Para Analisis tentang Web Services}

1. Gartner Group: “.NET is a brilliant strategy that enables Microsoft to define the next shift the software business.”

2. Meta Group: "Everyone should build on the XML/SOAP foundation."

3. Gartner Group: "Gartner believes Microsoft is now providing more vision and influence regarding this shift than any other vendor."

4. Patricia Seybold Group: ".NET is a leading example of what we believe will be the dominant architectural model for the third generation of internet applications."

\section{Net Roadmap}

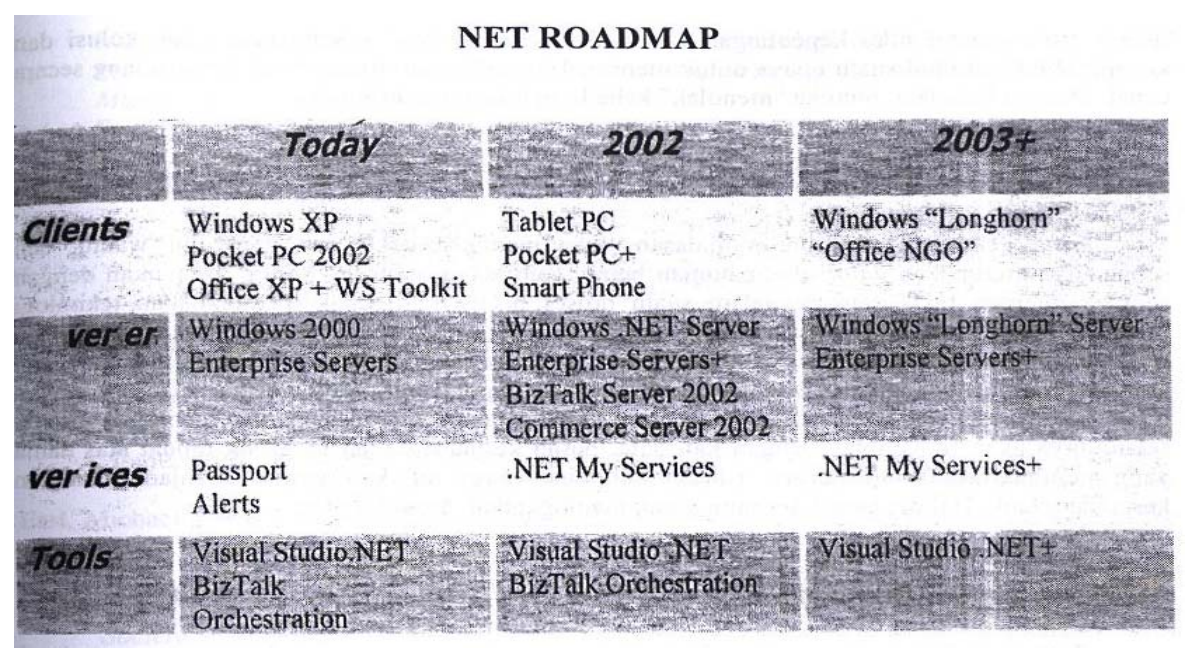




\section{Microsoft Sostware untuk Agile Business}

1. Platform yang paling lengkap untuk mengkoneksikan dunia.

2. Fleksibel dan sangat cepat.

3. Delivers best TCO.

4. Berfokus pada kepercayaan berkomputer.

5. .NET adalah realita hari ini.

\section{Isu Serta Tantangan dalam Implementasi Teknologi di Indonesia}

Secara garis besar, terdapat tiga aspek besar yang menjadi tantangan dalam membuat perubahan bisnis berdasarkan teknologi terutama di Indonesia.

\section{Aspek Politik}

Dengan adanya integrasi proses dan otomatisasi keputusan, akan “memotong” beberapa "kepentingan bisnis" yang sebenarnya "diharapkan” tidak bekerja sama satu sama lain. Maksudnya, proses hubungan bisnis yang semakin erat, cepat, dan terintegrasi di dalam teknologi informasi justru akan membuat birokrasi politik berkurang. Secara otomatis, orang yang berada dalam proses rantai nilai kepentingan bisnis akan "kehilangan” kesempatan untuk kolusi dan korupsi. Timbul suatu upaya untuk mencegah teknologi informasi tidak berkembang secara cepat. Dengan kata lain, mereka “menolak” kehadiran teknologi informasi.

\section{Aspek Budaya}

Sifat bekerja sambil malas-malasan, suka menunda pekerjaan, mengulur waktu, dan sebagainya merupakan naluri dasar human being. Kebiasaan buruk itu sering dilakukan dengan sengaja maupun tidak sengaja dalam suatu proses bisnis yang tidak menggunakan teknologi informasi. Jika suatu organisasi memakai teknologi informasi, dapat dipastikan bahwa kebiasaan tersebut tidak akan dilakukan kembali. Yang pasti, setiap proses bisnis akan menghasilkan keluaran (output) yang akan dipakai sebagai masukan (input) untuk proses bisnis selanjutnya. Jika tidak bekerja secara konsisten dan kontinu, sistem akan memperingatkan sehingga proses selanjutnya akan terhambat. Dengan kata lain, pesan kesalahan akan langsung dibuat atas nama yang membuat kesalahan. Secara "paksa," kebiasaan buruk itu akan berubah menjadi kebiasaan kerja yang baik. Hal itu sangat berguna untuk meningkatkan produktivitas.

\section{Aspek Bisnis (Organisasi)}

Teknologi informasi mungkin akan “memangkas” dan “merampingkan” suatu organisasi. Tujuan utama perampingan itu membuang suatu proses atau departemen yang tidak menghasilkan nilai tambah sehingga akan terjadi efisiensi. Teknologi informasi mungkin akan mengurangi kontribusi unit bisnis secara individu walaupun benefit untuk organisasi secara keseluruhan akan meningkat. Harus diperhatikan bahwa itu dapat menimbulkan 'perumahan” karyawan. Organisasi harus bijaksana dalam merumahkan karyawanya supaya tidak muncul konflik baru. Koordinasi dengan bagian HRD dan serikat karyawan akan menghasilkan solusi yang terbaik.

Secara keseluruhan, ketiga aspek tersebut merupakan tantangan terbesar dalam implementasi teknologi informasi. Namun, hambatan terbesar justru berada didalam organisasi itu sendiri. Jika diprediksikan, sumber daya manusia tidak akan bertahan untuk menolak kehadiran 
teknologi informasi. Barang siapa tidak dapat mengeksploitasi teknologi informasi, akan tertinggal jauh di belakang.

\section{PENUTUP}

\section{Simpulan}

Duet yang cukup harmonis antara bisnis dan teknologi informasi menjadi suatu kesatuan yang tidak dapat dipisahkan. Keduanya akan saling melengkapi. Pada akhirnya, dapat disimpulkan sebagai berikut.

1. Produksi komputer terus meningkat secara berganda setiap tahunya dan harga per unitnya semakin murah.

2. Perkembangan teknologi informasi semakin pesat melampaui perkembangan bisnis.

3. Organisasi mulai beralih ke organisasi maya dengan integrasi proses bisnis.

4. Integrasi terjadi antara organisasi maya dengan organisasi maya dan seterusnya.

5. Proses integrasi tidaklah mudah. Oleh karena itu, Microsoft menawarkan solusi dengan Microfot Enterprise Sotware.

6. Fokus bisnis adalah ke konsumen (pelanggan), yaitu menjual solusi bukan produk/jasa.

7. Tren sekarang dan masa depan adalah perangkat mobile.

\section{DAFTAR PUSTAKA}

Amor, Daniel. 1998. The Business Revolution. Prentice Hall.

Cash, James I et al. 1992. Corporate Information System Management. Edisi 3. Irwin: Homewood.

Earl, Michael J. 1998. Management Strategies for Information Technology. New York: Prentice Hall.

Fellenstein, Craig dan Ron Wood. 1999. Exploring E-Commerce, Global E-Business and ESociety. Prentice Hall.

Fingar, P, Harsha Kumar, dan Tarun Sharma. 2000. Enterprise E-Commerce. Meghan Kiffer Press.

Forcht, K.A. 1994. Computer Security Management. Massachusetts: Boyd and Fraser Company.

Hill, Charles W. L. 1997. International Business: Competing Global Marketplace. Irwin.

Kalakota, Ravi dan Andrew B. Whinston. 1996. Electronic Commerce A Managers Guide. Addison Wesley. 
1999. Ebusiness: Roadmap for Succes. Addison Wesley.

Levin dan Rubin. 1994. Statistic for Management. Edisi 6. New Jersey: Prentice Hall.

McLeod R. 1998. Management Information Systems: A Study of Computer Based Information Systems. Edisi 7. New Jersey: Prentice Hall.

Nielsen, Jacob. 1995. Multimedia and Hypertext: The Internet and Beyond. Academic Press. 1999. Designing Web Usability: The Pratice of Simplicity. New Riders Publishing.

O’Brien, James A. 2000. Introduction to Information Systems: Essentials for The Internetworked Enterprise. Edisi 9. Boston: Irwin/McGraw-Hill.

Plant, Robert T. 2000. Ecommerce: Formulation of Strategy. Prentice Hall.

Senn, James A. 1995. Information Technology in Business: Principles, Practises, and Opportunities. New Jersey: Prentice Hall.

Seybold, Patricia B. 1998. Customers.com: How to Create a Profitable Business Strategy for the Internet and Beyond. Times Books.

Turban, Efraim, Jae Lee, Jae Ktu Lee, David King, dan H. Michael Chung. 2002. Electronic Commerce A Management Perspective. 